\title{
Comparison of the Vi indirect fluorescent antibody test with the Widal agglutination method in the serodiagnosis of typhoid fever
}

\author{
NIVEDITA DOSHI, AG TAYLOR \\ From the Division of Microbiological Reagents and Quality Control, Central Public Health Laboratory, \\ Colindale Avenue, London NW9 5 HT
}

SUMMARY The indirect fluorescent antibody test using a whole Salmonella typhi Vi suspension as the antigen has been evaluated for the diagnosis of typhoid fever. Results using sera from 140 patients with $S$ typhi infections proved on culture show the test to have good sensitivity. The test appears to be highly specific, although it has not yet been investigated with respect to typhoid vaccination or in the context of infections due to salmonellas other than $S$ typhi.

The detection of Salmonella typhi Vi antibodies by an agglutination test as an aid to the detection of the typhoid carrier state was first recommended by Felix et al.' Limitations of the value of the test, however, have since been noted by various workers. ${ }^{23}$ Other serological techniques for the detection of $\mathrm{Vi}$ antibodies have been studied, including haemagglutination tests, ${ }^{45}$ counterimmunoelectrophoresis, ${ }^{6}$ and ELISA. ${ }^{7}$ The technically simple indirect fluorescent antibody test (IFAT) has been studied by Chau and $\mathrm{Chan}^{4}$ and by Chitkara and Urquhart, ${ }^{8}$ who concluded that this technique was superior to bacterial agglutination in both sensitivity and specificity. The IFAT is able to detect antibodies of all major classes, whereas agglutination tests favour the detection of IgM antibodies." We report the results obtained with the Vi IFAT in the serodiagnosis of acute typhoid fever compared with those obtained using the Widal reaction.

\section{Material and methods}

\section{SERUM SPECIMENS}

Patients with typhoid fever

Single or paired specimens were available from 140 patients with typhoid fever proved by isolation of $S$ typhi from blood or faeces. Most specimens had been stored at $-20^{\circ} \mathrm{C}$ for periods of up to five years. In 22 recent cases specimens were available which had been stored for a period of up to 1 week at $4^{\circ} \mathrm{C}$ but had not been frozen.
Patients without typhoid fever

Serum specimens were obtained from 68 patients diagnosed serologically as having infections caused by Legionella pneumophila (29), Leptospira (16), Staphylococcus aureus (11), and Streptococcus sp (12). Sera were also obtained from 12 patients with bacteriologically proved tuberculosis and from 30 patients with infections caused by Campylobacter jejuni. Sera from 66 patients with a fever of undetermined origin which were submitted to this division for serological tests for legionellosis were also tested, together with specimens from 284 apparently healthy blood donors.

\section{RABBIT ANTISERA}

Rabbit diagnostic agglutinating antisera used in defining the specificity of the IFAT antigen were prepared as described previously. ${ }^{10}$ These specific antisera had homologous tube agglutination titres of at least 320 and homologous IFAT titres of at least 128.

\section{AGgLUTINATION TESTS}

The antigens were the $S$ typhi $\mathrm{O}, \mathrm{H}$, and $\mathrm{Vi}$ agglutinable suspensions currently prepared as described previously $^{10}$ and as supplied by this Division to Public Health Laboratory Service laboratories in England and Wales. The tests were performed in tubes. ${ }^{10}$

IFAT

The antigen was the same whole bacterial antigen as used in the $\mathrm{Vi}$ agglutination test. It was prepared 
from the Bhatnagar strain of $S$ typhi (NCTC 8382) grown on agar and washed off in buffered formolsaline. After sterility testing the suspensions were treated with alcohol to remove $\mathrm{H}$ antigens and adjusted to a concentration of $8 \times 10^{4}$ organisms per $\mathrm{ml}$. For the IFAT this stock antigen (optical density at $605 \mathrm{~nm}=3 \cdot 2$, using $1 \mathrm{~cm}$ depth cell) was diluted $1 / 160$ in $1 \%$ homogenised normal yolk sac suspension to facilitate adherence of the antigen to the microscope slides. The method followed was as described previously." 12 Doubling serum dilutions from $1 / 16$ to $1 / 512$ were tested. Fluorescence intensity was scored,,++++++ , and - and the end point was the last dilution giving + fluorescence.

\section{Results}

AGGLUTINATION TITRES OBTAINED WITH SERA FROM PATIENTS WITH TYPHOID FEVER

Sufficient volumes of sera were available for $\mathrm{O}, \mathrm{H}$, and $\mathrm{Vi}$ tube agglutination tests as well as the $\mathrm{Vi}$ IFAT in 56 cases. The results are shown in Table 1. Stored sera showed fewer positive results in agglutination tests than recently obtained sera. The sensitivity of these agglutination tests, however, even using recently obtained sera, was poor in that a high proportion of sera gave negative results. In the case of the 22 recently ill patients, three had convalescent sera which were negative in all three agglutination tests (two were taken nine days after the onset of illness and one 17 days after onset). In contrast, the Vi IFAT titres of these sera were 128,512 , and 64 respectively.

\section{IFAT TITRES IN CONTROL SUBJECTS WITHOUT} TYPHOID FEVER

Titres of $<32$ were seen in $93 \%$ of 284 blood donors (Table 2). Similarly, $93 \%$ of sera from 110 patients with infections due to agents other than $S$ typhi showed titres of $<32$. Titres of $<32$ were found in $85 \%$ of patients with fever of undetermined origin, and in this group typhoid fever as the correct diagnosis was not ruled out.

Table 1 Comparison of Widal tests and IFAT for $V i$ antibodies using sera from 56 proved typhoid fever cases

\begin{tabular}{|c|c|c|c|c|}
\hline & \multicolumn{3}{|c|}{ Agglutination } & \multirow{2}{*}{$\frac{I F A T}{V i}$} \\
\hline & $T O$ & $T H$ & $V i$ & \\
\hline \multirow{4}{*}{$\begin{array}{l}\text { Titre considered positive } \\
\text { No of stored sera (34) } \\
\text { showing positive result } \\
\text { No of recent sera (22) } \\
\text { showing positive result } \\
\text { No of sera (56) showing } \\
\text { positive result }\end{array}$} & $\geqslant 80$ & $\geqslant 40$ & $\geqslant 5$ & $\geqslant 64$ \\
\hline & 4 & 18 & 10 & 33 \\
\hline & 11 & 15 & 7 & 22 \\
\hline & 15 & 33 & 17 & 55 \\
\hline
\end{tabular}

IFAT $=$ indirect fluorescent antibody test.
Table 2 Vi IFAT titres in 460 control subjects without typhoid fever

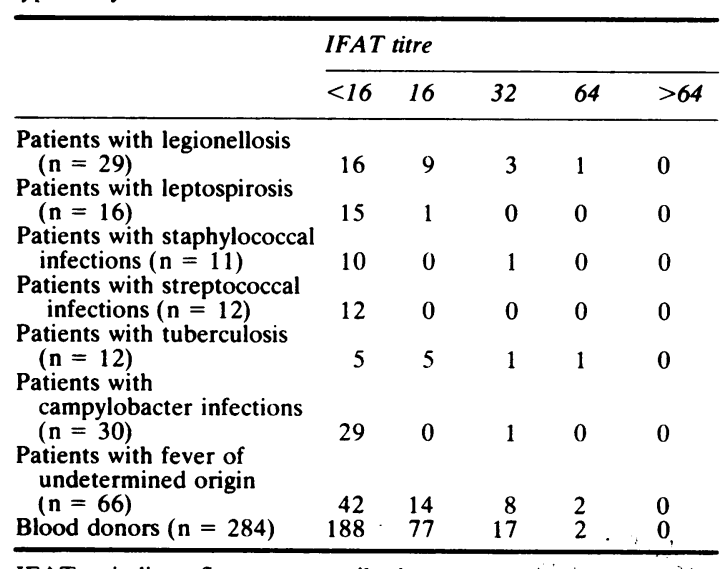

IFAT $=$ indirect fluorescent antibody test.

The possibility that typhoid vaccination may produce an antibody response detectable in the $\mathrm{Vi}$ IFAT is suggested by the finding that one of the patients with fever of undetermined origin who had a titre of 64 had received typhoid vaccine two months previously.

\section{IFAT TITRES IN 140 PATIENTS WITH PROVED TYPHOID FEVER}

Stored or recent sera from 140 patients were available in sufficient volume to permit the Vi IFAT to be performed. Results are shown in Table 3.

TIME OF VI IFAT SEROPOSITIVITY IN RELATION TO ONSET OF ILLNESS AND PREDOMINANT CLASS OF IMMUNOGLOBULIN PRODUCED

In 120 of the proved typhoid cases tested by the IFAT both the dates of the onset of illness and the dates when the sera were obtained were known. In four cases the serum was taken within three days of the onset of illness and all of these acute phase sera showed Vi IFAT titres of $\geqslant 128$. In nine patients the serum was taken between the 4 th and 7 th day after the onset of illness. Four of these sera had titres of 64 , four of 128 , and one of 256 , suggesting that the IFAT becomes positive early in the course of the disease. In 82 of the 120 cases the serum tested was

Table 3 Vi IFAT titres in 140 patients with proved typhoid fever

\begin{tabular}{llllll}
\hline & \multicolumn{6}{l}{ IFAT titre } \\
\cline { 2 - 6 } & $<32$ & 32 & 64 & 128 & $>128$ \\
\hline No of sera & 1 & 4 & 40 & 38 & 57 \\
\hline
\end{tabular}

IFAT $=$ indirect fluorescent antibody test. 
Table 4 Homologous IFAT and Vi IFAT titres of rabbit diagnostic agglutinating sera

\begin{tabular}{cccc}
\hline Antiserum & $\begin{array}{l}\text { Titre against } \\
\text { homologous antigen }\end{array}$ & $\begin{array}{l}\text { Titre against } \\
\text { Vi antigen }\end{array}$ \\
\hline O factor $\mathrm{Vi}$ & 128 & 128 \\
.. & 2 & 256 & 16 \\
.$*$ & 4 & 512 & 16 \\
.. & 6,7 & 512 & $<16$ \\
.. & 8 & 1024 & 16 \\
.. & 9 & 256 & 16 \\
.$*$ & 3.10 & 1024 & 16 \\
.. & 14 & 1024 & 16 \\
.. & 15 & 1024 & 16 \\
\hline
\end{tabular}

taken between the 8th and 30th day after/onset of illness, in 23 instances between the 31 st and 60th day, and in two cases after more than 60 days.

IgG and IgM antibodies were estimated independently in 80 cases using IgG or IgM specific FITC conjugates. Of the 80 sera 30 were recent nonfrozen specimens. The IgM titre was $\leqslant 16$ in 78 cases and $\mathrm{IgG}$ was the predominant class of antibody measured in the IFAT.

REACTIVITY OF ANTIBODIES TOOTHER SOMATIC ANTIGENS IN THE VI IFAT

Sera from patients with infections due to salmonella species other than $S$ typhi could not be obtained. In an attempt to define the specificity of the $\mathrm{Vi}$ antigen in the IFAT, tests were performed using rabbit diagnostic agglutinating antisera to a range of $O$ antigens of the most common salmonella serotypes. Results are shown in Table 4.

The results suggest that the common anti- $\mathrm{O}$ antibodies are not detected in the Vi IFAT and that the antibodies detected are directed against the $\mathrm{Vi}$ antigen. Results are similar to those obtained in the tube agglutination tests.

\section{Discussion}

Although the definitive diagnosis of typhoid fever is by culture of the causative organism usually from blood or faeces, serology can sometimes be helpful in providing a more rapid method of diagnosis. The diagnostic value of a serological test depends largely on its sensitivity and specificity. Judging by the results obtained so far the Vi IFAT described here is highly successful.

If an IFAT titre of 64 or greater is taken as serological evidence for the diagnosis of typhoid fever, only one of 56 sera from culture proved cases (Table 1) were falsely negative. In the agglutination tests most of these sera gave negative results in the $\mathrm{O}$ and $\mathrm{Vi}$ tests while just over one third were negative when tested against the $\mathrm{H}$ antigen. These results support the findings of Brodie, ${ }^{3}$ who found that the flagellar antibody titre in patients' sera provided a more reliable aid towards diagnosis than the somatic antibody titre, although the value of the Widal test in diagnosis was limited. The greater sensitivity of the Vi IFAT is striking and is confirmed in the larger series of patients (Table 3 ), where serum specimens from 135 of 140 patients showed positive titres $(\geqslant 64)$.

The results reported here on the specificity of the IFAT must be extended in further studies on sera from patients with other infections, including other salmonella infections, and in healthy subjects after typhoid vaccination. Nevertheless, the results in Table 2 suggest good specificity. Of 110 patients with infectious diseases other than typhoid fever only two had falsely positive titres of $\geqslant 64$. In the group of 66 patients with fever of undetermined origin only two had such titres and at least one of these had recently been vaccinated. In the case of healthy blood donors two of 284 sera were falsely positive. Overall, in this diverse group of 394 control subjects (excluding the 66 patients with a fever of undetermined origin) only four were falsely positive in the Vi IFAT.

Although various improvements in the $\mathrm{Vi}$ antibody test have recently been described which improve sensitivity and specificity, the IFAT has the advantage of using reagents which are readily available, and the test is technically simple. The IFAT also has the advantage of detecting all the major classes of antibody. Furthermore, we have previously shown that highly reproducible results can be obtained when this type of test is used in a large number of diagnositic laboratories..$^{13}$ We now propose to test its usefulness and reproducibility in field studies.

We thank Dr TD Davies of the North London Transfusion Centre for serum specimens from blood donors and all those who have sent us sera from cases of typhoid fever and other infections.

\section{References}

' Felix A, Krikorian KS, Reitler R. The occurrence of typhoid bacilli containing $\mathrm{Vi}$ antigen in cases of typhoid fever and of $\mathrm{Vi}$ antibody in their sera. J Hyg (Camb) 1935:35:421-27.

: Anderson ES. Richards HGH. An outbreak of typhoid fever in the Middle East. J Hyg (Camb) 1948;46: 164-72.

'Brodie J. Antibodies and the Aberdeen typhoid outbreak of 1964 1. The Widal reaction. J Hyg (Camb) 1977; 79:161-80.

+ Chau PY, Chan ACH. Modified Vi tests in the screening of typhoid carriers. J Hyg (Camb) 1976;77:97-104.

s Nolan CM. White PC. Feeley JC. Hambie EA. Brown SL. Wong $\mathrm{K}-\mathrm{H}$. Vi Serology in the detection of typhoid carriers. Lancet 1981:i:583-5.

- Tsang RS, Chau PY. Serological diagnosis of typhoid fever by counterimmunoelectrophoresis. Br Med J 1981;282: 1505-7. 
' Beasley WJ, Joseph SW, Weiss E. Improved serodiagnosis of Salmonella enteric fevers by an enzyme-linked immunosorbent assay. J Clin Microbiol 1981;13:106-14.

${ }^{8}$ Chitkara YK, Urquhart AE. Fluorescent Vi antibody test in the screening of typhoid carriers. Am J Clin Pathol 1979;72:87-9.

' Pike RM, Schulze ML, Chandler CH. Agglutinating and precipitating capacity of rabbit anti-Salmonella typhosa $\gamma \mathrm{G}$ and $\gamma \mathrm{M}$ antibodies during prolonged immunization. $J$ Bacteriol 1966;92:880-6.

${ }^{10}$ Bradstreet CMP, Bensted HJ, Taylor J, Carpenter WP, Anderson ES. Serological reagents for bacteriogical diagnosis. Monthly Bulletin of the Ministry of Health and the Public Health Laboratory Service 1961;20:134-49.

"Taylor AG, Harrison TG, Dighero MW. Bradstreet CMP. False positive reactions in the indirect fluorescent antibody test for Legionnaires' disease eliminated by use of formolised yolk-sac antigen. Ann Intern Med 1979;90:686-9.

${ }^{12}$ Harrison TG, Taylor AG. Diagnosis of Legionella pneumophila infections by means of formolised yolk sac antigens. J Clin Pathol 1982;35: 211-4.

${ }^{13}$ Taylor AG, Harrison TG. Serological tests for Legionella pneumophila Serogroup 1 infections. Zentralbl Bakteriol Hyg (Orig A) 1983;255:20-6.

Requests for reprints to: Dr AG Taylor, Central Public Health Laboratory, Division of Microbiological Reagents $\omega$ and Quality Control, 175 Colindale Avenue, London $\overrightarrow{0}$ NW9 5HT, England. 